\title{
Concepções e práticas de avaliação da aprendizagem no ensino superior: implicações na formação de licenciandos em Matemática
}

\author{
Conceptions and practices of evaluation of learning in higher education: \\ implications in licensing training in Mathematics
}

\author{
Raimundo Hélio Leite* \\ Antônia Edivaneide de Sousa Gonzaga** \\ Karlane Holanda Araújo ${ }^{* *}$
}

\section{Resumo}

No presente artigo, discutem-se as concepções de avaliação da aprendizagem dos professores do curso de licenciatura em Matemática do Instituto Federal de Educação, Ciência e Tecnologia da Paraíba, Campus Cajazeiras, e suas influências nas práticas avaliativas na formação docente. A pesquisa, de caráter descritivo, de abordagem predominantemente qualitativa, teve como sujeitos vinte professores do curso supracitado. Foram utilizados como instrumentos metodológicos de coleta de dados questionários e entrevistas semiestruturadas, abordando aspectos relacionados às concepções de educação, avaliação da aprendizagem e formação docente. Os dados coletados por meio das entrevistas foram discutidos à luz do enfoque fenomenológico, com base na hermenêutica gadameriana. A partir da fusão de horizontes presentes nas falas dos profissionais participantes da pesquisa, foi possível estabelecer reflexões sobre o papel assumido efetivamente pela avaliação do ensino-aprendizagem no cenário da formação de docentes no Instituto Federal de Educação, Ciência e Tecnologia da Paraíba, Campus Cajazeiras. Concluiu-se, dentre outros aspectos, que há necessidade de se desenvolver, no contexto pesquisado, um trabalho sistemático acerca da avaliação da aprendizagem, visando à superação das práticas avaliativas tradicionalistas desenvolvidas com os alunos da licenciatura em Matemática.

Palavras-chave: Concepções de avaliação. Formação docente. Práticas avaliativas.

Recebido em 19/04/2018 - Aprovado em 28/08/2018

http://dx.doi.org/10.5335/rep.v26i1.8440

Professor Dr. Livre-Docente do Programa de Pós-Graduação em Educação Brasileira da Universidade Federal do Ceará (UFC). Coordenador da linha de pesquisa em Avaliação Educacional do curso de mestrado e doutorado em Educação Brasileira da UFC. E-mail: rhleite@terra.com.br

** Doutoranda e mestra em Educação Brasileira pela Universidade Federal do Ceará (UFC) - Linha de Avaliação Educacional. Professora do Instituto Federal de Educação, Ciência e Tecnologia da Paraíba (IFPB). E-mail: <edivaneidesousa2012@gmail.com>.

*** Doutoranda e Mestra em Educação Brasileira, pelo Programa de Pós-Graduação em Educação, da Universidade Federal do Ceará - UFC - Linha de Avaliação Educacional - e especialista em Gestão e Avaliação da Escola Pública pela Universidade Federal de Juiz de Fora (UFJF). Professora do Instituto Federal de Educação do Ceará (IFCE) - Campus Ubajara. E-mail: karlane.araujo@ifce.edu.br 


\section{Abstract}

This paper, discuss the evaluation conceptions of the learning of teachers in course Mathematics on Federal Institute of Education, Science and Technology of Paraíba, Campus Cajazeiras, and their influences on the evaluative practices in the teacher formation. The research, presented descriptive, with a predominantly qualitative approach, had as subject 20 (twenty) teachers of the course above mentioned. Methodological tools were used to collect data questionnaires and semi-structured interviews, addressing aspects related to conceptions of education, evaluation of learning and teacher training. The data collected through the interviews were discussed based on the phenomenological approach, structured on Gadamerian hermeneutics. From the fusion of horizons present in the speeches of the professionals participating in the research, it was possible to establish reflections on the role assumed effectively by the evaluation of teaching-learning in the scenario of teacher training at the Federal Institute of Education, Science and Technology of Paraíba, Campus Cajazeiras. The conclusion denotes, among other aspects, is essential to develop, in the context studied, a systematic work on the evaluation of learning, aiming at overcoming the traditionalist evaluation practices developed with the undergraduate students in Mathematics.

Keywords: Evaluation concepts. Teacher training. Evaluation practices.

\section{Introdução}

Nenhuma ação pedagógica realizada em sala de aula é neutra. Ela vem sempre carregada de crenças, concepções e reflexos de outras experiências. Dessa forma, o olhar do professor sobre o processo de ensino conduz a determinadas ações, visando a atender às demandas decorrentes de suas intencionalidades e de seus objetivos. A concepção de avaliação do docente guia todo o processo de ensino-aprendizagem, desde o planejamento das ações didáticas até a execução delas. A forma como cada um concebe esse processo de construção de conhecimentos é o que direciona toda a sua prática docente. Assim também acontece quando se trata da avaliação da aprendizagem no ensino superior, tendo em vista que a escolha dos instrumentos avaliativos, do momento em que se avalia, da maneira como se avalia, das ênfases dadas ao ato de avaliar, tudo isso é conduzido pelo ponto de vista, pela concepção que cada professor tem sobre o que é avaliar.

Embora existam diferentes estratégias de avaliação destinadas a aferir o ensino superior, de modo geral, a exemplo do Sistema Nacional de Avaliação do Ensino Superior (Sinaes), ainda é difícil se avaliar a atuação docente de forma mais específica, de modo a se refletir sobre o nível de alcance de cada ação e a relação estabelecida com essas práticas docentes em médio e longo prazo. Ao passo que o Sinaes avalia os cursos por meio de três componentes: a avaliação das instituições, dos cursos e do desempenho dos estudantes; nestes ainda não são contempladas claramente as práticas desenvolvidas por cada professor, nesse processo de formação, a exemplo das abordagens acerca da avaliação da aprendizagem. $\mathrm{O}$ próprio instrumento que direciona a avaliação dos estudantes do ensino superior, o Exame Nacional de Desempenho dos Estudantes (Enade), que tem como obje- 
tivo avaliar conhecimentos, habilidades, saberes e competências adquiridas ao longo da formação, gera subsídios que atenderão mais a uma avaliação externa, ainda que abordem questões específicas da formação e suas concepções nos cursos como um todo (POLIDORI; MARINHO-ARAÚJO; BARREYRO, 2006). Dessa forma, os aspectos específicos da avaliação da aprendizagem não são mensurados no instrumento em questão e, principalmente, como os futuros professores serão preparados para o desenvolvimento de práticas avaliativas em situações futuras, de modo a se estabelecer a devida relação entre a teoria e a prática docente.

Nesse contexto, é importante destacar algumas concepções de avaliação por parte dos docentes, a fim de situá-las de acordo com determinadas práticas que vêm sendo pensadas e empreendidas nas instituições de ensino e nos contextos de formação docente nos dias atuais. Para tanto, é necessário refletir a respeito das questões a seguir: como se constituem as práticas avaliativas desenvolvidas nas escolas atualmente? Que concepções de avaliação ou de educação fundamentam essas práticas?

Diante desses questionamentos, surgiu a intenção de se desenvolver o presente estudo a fim de se discutir sobre a forma como a avaliação é desenvolvida no contexto da formação docente, de modo mais específico, no processo de formação inicial do professor de Matemática.

O artigo está organizado em cinco seções. A primeira conta com esta breve introdução. Em seguida, apresenta-se a abordagem teórica acerca das concepções de avaliação da aprendizagem, dos conceitos atribuídos às práticas avaliativas numa perspectiva mais voltada para a avaliação formativa e como esses conhecimentos e experiências se articulam como subsídios para atuação dos futuros professores de Matemática. Na sequência, explicitam-se os procedimentos metodológicos utilizados na investigação e, por fim, são descritos os principais aspectos considerados na análise, seguidos da reflexão sobre cada um deles. A parte final do artigo é composta pelas considerações acerca do estudo realizado, apontando-se os resultados obtidos.

\section{Das concepções de avaliação da aprendizagem}

Ao se falar de avaliação da aprendizagem, ainda há muitas incógnitas, muitas incertezas que precisam ser superadas, tendo em vista uma busca por práticas diferenciadas, inovadoras em sala de aula, que, não raro, já estão presentes nos discursos dos professores, porém, ao se analisar tais práticas, percebe-se que elas ainda se configuram estritamente como tradicionalistas. 
No que diz respeito à relação estabelecida entre o que se fala e as práticas efetivas dos professores em sala de aula, convém destacar a contribuição de António Nóvoa (1999), quando escreve sobre os aspectos antagônicos presentes nas falas dos docentes ou até mesmo nas próprias políticas públicas relacionadas à educação. Nesse contexto, há, muitas vezes, um excesso de discursos e uma notável pobreza nas práticas, na forma como elas se concretizam. Para ele, “[...] 0 excesso dos discursos esconde a pobreza das práticas políticas” (NÓVOA, 1999, p. 13). Esse distanciamento entre o que se fala e o que se pratica, por vezes, tende a mascarar ações que poderiam ser repensadas ou até mesmo melhoradas no contexto da ação pedagógica.

Aspectos mais gerais da formação do professor, inclusive, revelam esse entrave. Há o interesse em se trabalhar a avaliação sob outra perspectiva, sob olhares diferenciados, contudo a maioria dos docentes não está preparada. A esses profissionais ainda é atribuída uma carga enorme, que, em consequência, acarreta angústias sobre sua função no processo educacional, o que pode gerar até mesmo uma crise de identidade e o adoecimento dos docentes.

Assim, de modo geral, há uma ambiguidade no próprio discurso em se tratando da funcionalidade dos professores em paralelo com sua formação docente.

Por um lado, os professores são olhados com desconfiança, acusados de serem profissionais medíocres e de terem uma formação deficiente; por outro lado, são bombardeados com uma retórica cada vez mais abundante que os considera elementos essenciais para a melhoria da qualidade do ensino e para o progresso social e cultural (NÓVOA, 1999, p. 13-14).

Nesse sentido, é interessante repensar a maneira como cada um se enxerga dentro do sistema educacional no qual se insere: quais as atribuições direcionadas a esses professores? Como a gestão da instituição pensa a prática docente? Como são encaradas as abordagens curriculares? Enfim, há todo um sistema carregado de concepções que precisam ser consideradas. Essas questões ganham maior importância quando se entende que não há possibilidade de se empreender práticas educativas diferenciadas, inovadoras, se a concepção do professor ainda está enraizada num modelo pedagógico estritamente tradicional, ou se o próprio sistema/contexto no qual o professor está inserido ainda encara a ação pedagógica de forma reducionista, visualizando cada prática e cada ação de forma isolada.

Pensar a avaliação educacional requer o olhar sobre questões mais amplas, conceitos mais complexos, que envolvem toda a prática pedagógica. É necessário perceber o grau de importância atribuído ao processo educativo, os valores que permeiam o conceito de educação, para que se possa emitir um posicionamento sobre as práticas que se constituem nos espaços educacionais. No que se refere à avaliação educacional, é preciso ir mais além, buscando inserir a prática num 
contexto em que se valorize mais a condição humana, tendo em vista a superação do aspecto meramente voltado para a mensuração, uma vez que nem tudo que se vivencia em sala de aula é passível de ser aferido. Nesse sentido, Biesta contribui com a seguinte reflexão: "[...] para reintroduzir questões de valor e propósito nas discussões sobre educação, principalmente em situações em que a mensuração aparece proeminentemente, precisamos reinserir a questão do que constitui uma boa educação" (2012, p. 813).

É preciso compreender quais conceitos são atribuídos à prática docente, desde as pequenas até as mais complexas ações, como é o caso da avaliação da aprendizagem. A avaliação precisa ser visualizada em suas especificidades, embora não se possa perder de vista a análise contextual, abrangendo, de forma mais ampla, toda a realidade na qual ela está inserida. Dessa forma, há que se considerar que:

[...] um foco mais preciso no que constitui uma boa educação é crucial para a forma como abordamos todas as dimensões da educação e, principalmente, para os aspectos com que nos comprometemos mais explicitamente nas questões de valores, como nos campos da avaliação do ensino, da avaliação educacional e em relação a questões sobre responsabilização (accountability) (BIESTA, 2012, p. 813-814).

Vale ressaltar que a ação e as atividades docentes não estão ou não devem estar a serviço apenas das respostas que precisam ser dadas a um sistema educacional e que, por sua vez, nem todos os resultados obtidos por meio desse processo podem ser mensurados. Existem situações nas quais os pequenos atos, os aspectos mais simples do cotidiano de sala de aula, precisam ser norteados por uma concepção bem definida do que seja de fato a relação estabelecida entre o ensino e a aprendizagem, entre o professor e o aluno, entre as possibilidades de construção de conhecimento, que, na maioria das vezes, não são ditadas ou definidas em perspectivas mais amplas em contextos de programas educacionais. Cada sujeito, cada protagonista do processo, precisa compreender bem os objetivos almejados, os valores que norteiam suas práticas, as ponderações que precisam ser feitas durante o processo, enfim, as concepções de educação e, consequentemente, de avaliação que norteiam o seu pensar e o seu agir em sala de aula.

De acordo com Andriola, deve-se sempre ter em mente "[...] que o propósito de toda e qualquer sistemática avaliativa é fornecer subsídios para que os responsáveis pela coordenação e planejamento de ações educativas possam tomar decisões, visando ao seu aperfeiçoamento" (2012, p. 149). Segundo ele, cabe ao professor, ao avaliar seus alunos, julgar também sua atuação docente, se os procedimentos pedagógicos utilizados estão de fato atingindo os objetivos desejados no que diz respeito ao aprendizado dos discentes. 
Nessa perspectiva, a concepção de avaliação da aprendizagem gira em torno de uma atividade que perpassa e ultrapassa momentos específicos ou pontuais pensados e propostos em sala de aula. Ela vai muito além. Envolve toda a ação pedagógica, desde a concepção de educação até a adoção de práticas docentes que venham a contemplar as diversas instâncias da sala de aula, do fazer pedagógico.

O professor, como um dos protagonistas do processo avaliado, precisa ter a consciência de que sua ação também deve ser passível de avaliação, objeto de reflexão. A ação docente não deve ser deixada à margem do processo avaliativo. Tendo claras essas questões, o professor terá definida uma concepção de avaliação, encarando-a como aspecto norteador de suas ações, desde o planejamento até a execução e avaliação de práticas empreendidas no universo da sala de aula.

A educadora Maria Tereza Esteban descreve a avaliação como:

[...] um dos eixos centrais da educação, porque através dela é que a gente pode ir equilibrando esse processo, tendo algumas contribuições durante o próprio processo e não apenas após o seu efeito já estabelecido, já visualizado, enfim, a gente pode ir regulando as nossas próprias práticas (2004, p. 1).

Nesse contexto, a avaliação envolve um conjunto de práticas desenvolvidas no interior da escola e tem um caráter contínuo, sendo realizada em paralelo a toda e qualquer atividade empreendida na busca da construção do aprendizado do aluno.

Se a avaliação educacional é pensada numa perspectiva mais ampla, o conceito também se amplia e o processo avaliativo ganha maior abrangência. A avaliação, inserida num universo maior, que é a educação, não é ou não deve ser concebida de forma isolada. A concepção norteadora de um programa educacional fornece os subsídios básicos para orientação das práticas oriundas desse sistema. De acordo com Silva:

[...] a Avaliação Educacional, fundada numa visão crítica de Educação, assume um compromisso de ser um processo formativo que contribui para a construção da qualidade social das políticas e dos programas educacionais, não tendo a missão de classificar e nem de criar ranqueamento entre as instituições e os indivíduos da educação (2012, p. 10).

Concebida nessa perspectiva, a avaliação assume de fato um papel que vai além das práticas avaliativas ou da aplicação de instrumentos avaliativos em sala de aula. A avaliação será posta na intenção de oferecer subsídios para a construção do aprendizado dos estudantes, apesar de visar, também, ao atendimento dos objetivos elencados numa instância maior, o caso dos programas educacionais.

Muitas são as críticas lançadas à Pedagogia tradicional, embora muitas das práticas realizadas hoje em sala de aula recorram exatamente a princípios decorrentes dessa concepção pedagógica. Têm sido colocados à prova diversos recursos metodológicos utilizados na escola, sob pena de não favorecerem o processo criativo 
dos alunos; dentre esses mecanismos, a avaliação e a ação direta do professor têm recebido atenção especial nesses posicionamentos críticos.

[...] a compreensão da natureza da educação enquanto um trabalho não material, cujo produto não se separa do ato de produção, permite-nos situar a especificidade de educação como referida aos conhecimentos, ideias, conceitos, valores, atitudes, hábitos, símbolos sob o aspecto de elementos necessários à formação da humanidade em cada indivíduo singular, na forma de uma segunda natureza, que se produz, deliberada e intencionalmente, através de relações pedagógicas historicamente determinadas que se travam entre os homens (SAVIANI, 2011, p. 20).

Diante disso, precisa-se compreender que nem a escola nem a educação como um todo se situam de forma isolada, existe um contexto que as cerca, o qual vem carregado de concepções, sejam elas ligadas aos aspectos sociais, políticos e econômicos, ou à forma como se concebe o mundo e as relações que nele se constituem.

$\mathrm{Na}$ visão de Libâneo, a avaliação escolar é definida como “[...] componente do processo de ensino que visa, através da verificação e qualificação dos resultados obtidos, determinar a correspondência destes com os objetivos propostos e, daí, orientar a tomada de decisões em relação às atividades didáticas seguintes" (1994, p. 196). Partindo dessa afirmação, convém acrescentar que ela não se configura como um aspecto isolado dos demais, tendo em vista que fornece subsídios para práticas seguintes, constituindo-se fator instigante da reflexão das ações cotidianas do professor.

Assim, cabe acrescentar a afirmação de Vianna, ao enfatizar que:

[...] a avaliação nunca é um todo acabado, autossuficiente, mas uma das múltiplas possibilidades para explicar um fenômeno, analisar suas causas, estabelecer prováveis consequências e sugerir elementos para uma discussão posterior, acompanhada de tomada de decisões, que considerem as condições que geraram os fenômenos analisados criticamente (2000, p. 18).

Nesse sentido, há que se considerar que "[...] a avaliação educacional, no conjunto do pensamento pedagógico, não gera verdades incontestáveis, mas formula argumentos plausíveis para a análise e, possivelmente, a explicação do que constitui objeto da reflexão do avaliador" (VIANNA, 2000, p. 19). Parte-se da premissa de que os estudos relacionados à avaliação educacional não serão tratados como verdades absolutas, mas sim como construtos de uma concepção de educação que priorize em seu escopo um espaço privilegiado para as práticas educacionais, bem como para a avaliação da aprendizagem. 


\section{A avaliação formativo-reguladora como alternativa ao processo de formação inicial do professor de Matemática}

As constantes modificações nos cenários educacional e social têm fomentado a busca pela ressignificação da prática docente. À escola vêm sendo atribuídas diversas funções sociais, que, por sua vez, têm dificultado o processo de ensino e, consequentemente, de aprendizagem dos educandos, tendo em vista os papéis distintos que lhe são designados. Diante desse contexto, a prática docente se torna mais complexa, tendo exigido um desdobramento maior dos professores diante da intencionalidade de atender às demandas que lhe são postas ou impostas em sala de aula.

Dessa forma, as práticas que se desenvolvem no âmbito da sala de aula têm assumido características também diferenciadas, de modo especial aquelas ligadas à avaliação da aprendizagem. Essas práticas podem assumir características positivas ou negativas no cotidiano dos discentes. Fatores que podem diferenciar o nível de alcance/resultado de tais práticas são a abordagem utilizada pelo professor e a concepção que a norteia. Elas podem tanto promover o aluno, ao passo que $o$ motivam para a busca de novos conhecimentos, como também desmotivá-lo, ao passo que configuram um processo de exclusão, adquirindo um caráter negativo no cotidiano dos educandos.

Diversas questões se apresentam quando se pensa em avaliação da aprendizagem, principalmente no que diz respeito às formas de avaliar ou, especificamente, a: como avaliar? Que tipo de abordagem atenderá aos propósitos ou objetivos do ensino? Que fundamentos epistemológicos da avaliação nortearão tais práticas? Esses aspectos precisam ser refletidos, esclarecidos, não somente pelo professor de forma isolada, mas por todo o conjunto, pela escola e até mesmo pelo sistema educacional no qual está inserido.

Antes de se definir o tipo de avaliação que se deseja praticar, é importante também a definição do que se vislumbra de fato a partir das práticas empreendidas, ou seja, que objetivos ou metas são pretendidos.

Se a avaliação é pensada numa perspectiva mais voltada para a valorização do diálogo, da reflexão acerca dos resultados que são visualizados no dia a dia em sala de aula, do processo utilizado para se chegar a determinados resultados rumo à aprendizagem, então é possível que essa avaliação esteja direcionada para o que Perrenoud (1999) denomina como avaliação formativa.

A avaliação formativa tende a mover estruturas relativas não só ao processo de formação e construção do saber por parte do aluno, como também ao processo de formação e atuação do professor. Trata-se de "[...] uma avaliação que ajude o aluno 
a aprender e o professor a ensinar" (PERRENOUD, 1999, p. 144). Dessa forma, a avaliação assume o papel de regulação, tanto das ações do professor, por meio da busca por uma otimização de tais ações, quanto dos resultados alcançados, por meio do processo de aprendizado do aluno.

Nessa perspectiva, a concepção de avaliação adquire um formato diferenciado, em que o olhar é voltado principalmente para o processo, o caminho percorrido para se chegar aos resultados, bem como para as intervenções realizadas visando à otimização desse processo. "Essa concepção se situa abertamente na perspectiva de uma regulação intencional, cuja intenção seria determinar ao mesmo tempo o caminho já percorrido por cada um e aquele que resta a percorrer com vistas a intervir para otimizar os processos de aprendizagem em curso" (PERRENOUD, 1999, p. 89).

É interessante destacar o conceito atribuído à regulação, de modo especial à regulação dos processos de aprendizagem. Apesar de suscitar uma abordagem ampla, Perrenoud a define como "[...] o conjunto de operações metacognitivas do sujeito e de suas interações com o meio que modificam seus processos de aprendizagem no sentido de um objetivo definido de domínio" (1999, p. 90). Portanto, a regulação da aprendizagem é viável quando se tem objetivos bem definidos quanto ao que se espera do estudante em termos de aquisição/construção de conhecimentos, em que o docente adquire subsídios para a regulação das ações que integram o processo, com vistas à otimização da trajetória percorrida pelo aluno em busca de tais objetivos, que, por sua vez, convergem para a aprendizagem.

Nesse sentido, é interessante considerar o processo percorrido pelo discente no que se refere à construção da aprendizagem, assim como os propósitos/objetivos que norteiam a prática da avaliação como um todo. Assim:

A avaliação existe para que se conheça o que o aluno já aprendeu e o que ele ainda não aprendeu, para que se providenciem os meios para que ele aprenda o necessário para a continuidade dos estudos. [...] Não se avalia para atribuir nota, conceito ou menção. Avalia-se para promover a aprendizagem (VILLAS BOAS, 2004, p. 29).

Um aspecto forte associado à avaliação formativa é a observação realizada, principalmente pelo professor. Através do ato de observar, torna-se possível identificar os pontos que precisam ser retomados na prática cotidiana, nas relações professor-aluno, aluno-conhecimento, aluno-aluno, e assim por diante. Somente a partir de um exercício constante de observação é que será possível implementar uma proposta de intervenção com base nos resultados ou respostas com os quais se tem contato em sala de aula cotidianamente. Vale lembrar que essa observação será sempre guiada por um conjunto de fatores, sobretudo pelos 
objetivos que compõem o plano de avaliação traçado para cada situação prevista e realizada em sala de aula.

Essa mudança de conceito, ou, por que não dizer, de paradigma, remete à necessidade de se pensar e praticar uma avaliação da aprendizagem que assuma um caráter diferenciado, o que exige uma nova compreensão de aluno, do processo de ensino, da construção da aprendizagem. Nessa perspectiva, faz jus considerar as contribuições de Silva (2013) acerca da avaliação da aprendizagem na perspectiva formativo-reguladora, que, por sua vez:

[...] insere-se numa prática pedagógica intelectual reflexiva transformadora, por exigir do professor e da professora que sejam intelectuais, autores e atores de sua ação docente, e reflexiva transformadora no sentido da capacidade epistemológica de criar e de remodelar o seu trabalho, transformando os conhecimentos científico, artístico e popular em saberes escolares contextualizados (2013, p. 13).

Na busca dessa regulação, visando à otimização do processo de construção da aprendizagem, entra em cena o conceito de aprendizagem significativa. O que se configura como uma aprendizagem que seja de fato significativa? Na busca desse entendimento, Silva (2013) destaca que o paradigma da aprendizagem significativa tende a motivar o processo de ressignificação do ensino e da aprendizagem, tendo em vista a necessidade de se considerar com mais intensidade o nível de potencialidade que o aluno possui de aprender em detrimento do que ele não foi capaz de construir em termos de aprendizado.

Dessa maneira, a prática docente assume características diferenciadas, em que o espaço educativo precisa ser visto de forma dinâmica, como um ambiente de construção ativa. É preciso compreender que o conhecimento não se dá de forma estática, passiva. Essa construção move diversas estruturas, como a cognitiva e a afetiva; para que isso aconteça, há que se encarar uma mudança de postura, de modo especial por parte do professor, que deve fazer desse espaço e das ações que acontecem nele objetos de reflexão, de investigação constante, tendo como foco a aprendizagem e, principalmente, as estruturas articuladas no processo de construção do aprendizado dos discentes.

A avaliação, encarada como possibilidade de construção de conhecimentos, deve garantir ao estudante a oportunidade de interação com as mais diversas situações didáticas, as quais tenham como objetivo a coleta do maior número possível de informações. 
Para ter sentido, a avaliação em sala de aula deve ser bem fundamentada quanto a uma filosofia de ensino que o professor espose. A partir dessa premissa, o professor pode acumular dados sobre alguns tipos de atividades, provas, questões ou itens ao longo do seu trabalho, criando um acervo de referência para suas atividades de avaliação dentro de seu processo de ensino. É de todo importante que o professor possa criar, e verificar no uso, atividades diversas que ensejem avaliação de processos de aquisição de conhecimentos e desenvolvimento de atitudes, de formas de estudo e trabalho, individual ou coletivamente, para utilizar no decorrer de suas aulas (GATTI, 2003, p. 99).

Essas informações terão como objetivo oferecer o suporte necessário para a adoção de procedimentos relacionados ao ato de avaliar. Serão os instrumentos que permitirão ao professor um olhar mais amplo sobre o processo de ensino, não limitando a avaliação somente à ação de atribuir notas.

Entretanto, na maioria das situações em sala de aula, o que se observa é que os alunos, muitas vezes, não têm o conhecimento dos objetivos das ações voltadas para a avaliação. Além disso, é comum o uso de instrumentos nos quais não são muito claras as intenções do professor e o real objetivo para a realização de tal atividade, tampouco a concepção envolvida em tal prática.

Ao se pensar na prova como um dos instrumentos avaliativos mais utilizados, é interessante destacar qual sua real função. Esse instrumento é utilizado a serviço de quem? Visa atender a que tipos de objetivos? É utilizado em quais instâncias da prática docente? O que é feito com os dados/resultados obtidos por meio da realização da prova? Nesse sentido, Moretto vem corroborar a ideia de que a prova não tem um fim em si mesma e que também não deve ser descartada após a atribuição da nota, ao contrário:

Não é preciso condenar a prática de provas escritas como sendo a vilã do fracasso escolar. Professores não precisam ter vergonha de afirmar que avaliam a aprendizagem de seus alunos também (enfatizo o também) por meio de provas escritas, individuais, em grupo, com ou sem consulta, marcadas de tempos em tempos, por eles ou nos calendários escolares. $\mathrm{O}$ que precisa ser feito é ressignificar o conceito destas atividades, ou seja, tomando-as como instrumentos para recolher 'sinais' que serão interpretados como indicadores da eficiência dos processos de ensino e de aprendizagem, os quais têm como objetivo final a construção de procedimentos pelo sujeito do processo educativo: 0 aluno (2010, p. 55, grifos do autor).

Assim, os resultados de uma avaliação não estão atrelados somente ao tipo de instrumento que é utilizado, entretanto é necessário reconhecer que a maneira como eles são encarados ou praticados e o uso que é feito dos resultados oriundos das práticas avaliativas fazem toda a diferença.

É interessante como outros instrumentos avaliativos vão sendo inseridos nas práticas pedagógicas e como as relações estabelecidas entre o ensino e a forma de avaliação vão também se modificando. Porém, é pertinente destacar a necessidade de estar alerta para o uso de instrumentos diferenciados de avaliação, tendo em 
vista que o que vai diferenciar uma prática da outra não é somente o instrumento em si. É preciso todo um processo de preparação, tanto das aulas quanto da aplicação desses instrumentos, no sentido de otimizar tais práticas. Portanto, é necessário pensar, numa perspectiva maior, o potencial de cada um e quais os produtos esperados em decorrência de seu uso.

Outro fator importante na escolha e utilização dos instrumentos avaliativos é o cuidado relacionado aos procedimentos em decorrência da utilização de cada instrumento. Cada um deles oferece possibilidades diferenciadas de acordo com a maneira como é empregado, ou seja, os resultados coletados têm uma relação direta com o emprego dos instrumentos de avaliação na prática docente.

De nada adianta o professor lançar propostas diferenciadas com o uso de diferentes instrumentos, como seminários, relatórios, debates, etc., se não há, em sala de aula, nas situações corriqueiras, por exemplo, o espaço privilegiado para o debate, para o diálogo, enfim, se esses aspectos mais construtivos do conhecimento não fazem parte de uma vivência do aluno. Hoffmann corrobora essa ideia defendendo a necessidade de se entender primeiro "[...] como os educadores pensam a avaliação, antes de mudar metodologias, instrumentos de testagem e formas de registro. Reconstruir as práticas avaliativas sem discutir o significado desse processo é como preparar as malas sem saber o destino da viagem" (2005, p. 13). Assim, antes de se pensar na mudança de modelos ou paradigmas de avaliação, é preciso compreender a concepção que se tem do ato de avaliar, considerando inclusive todas as possibilidades presentes nessa ação.

Nesse sentido, Esteban (2008) enfatiza a importância de analisar as práticas dos professores de maneira mais criteriosa, considerando as formas de abordagem e as intencionalidades presentes em cada uma delas, tendo em vista que:

É na escola que encontro pistas e evidências de que a avaliação precisa transformar-se e de que diariamente ela vem sendo transformada por quem a realiza. Às vezes, uma atividade aparentemente igual ganha sentidos diferentes; outras práticas, que se auto-proclamam novas ou transformadoras, não passam de reedições das práticas às que criticam (2008, p. 30).

No espaço de múltiplas vivências, de inúmeras possibilidades, no qual se constitui a escola, as relações que se estabelecem a partir das práticas realizadas devem ser consideradas. Nesse contexto, os professores e os aspectos constitutivos de sua formação, de sua identidade, ganham maior abrangência, tendo em vista que a forma como visualizam todo o processo educativo tende a fazer a diferença nas formas de pensar e de desenvolver as práticas cotidianas.

A avaliação da aprendizagem está vinculada a uma série de fatores que atuam como constituintes da prática/ação de avaliar. Estes, por sua vez, dividem-se em fa- 
tores internos e externos. Os fatores externos são compreendidos como aqueles que independem da vontade do professor, que, não raro, são impostos pelo sistema educacional, por exemplo. Já os internos compreendem aqueles aspectos constitutivos da identidade do professor, aspectos diretamente relacionados à sua identidade, resultantes de sua formação e das reflexões geradas a partir de sua ação.

Convém destacar a importância da formação inicial docente nesse processo de concepção e desenvolvimento das práticas inerentes à avaliação da aprendizagem. Ao analisar a forma como o professor concebe a avaliação e a maneira como essas práticas são empreendidas no contexto da licenciatura, refletir-se-á melhor sobre o olhar direcionado a futuras práticas avaliativas, considerando-se que os futuros professores tendem a sofrer influências dos modelos com os quais tiveram contato em sua formação, como forma de reprodução ou de negação/superação.

\section{Metodologia}

A pesquisa realizada é do tipo descritiva, haja vista que "[...] visa descrever e caracterizar fenômenos e populações, estabelecendo relações entre variáveis intervenientes e fatos" (MARQUES et al., 2006, p. 52). Neste caso específico, foi utilizada a fenomenologia como método de investigação e análise, sendo enfatizadas as contribuições da hermenêutica de Hans-Georg Gadamer (1900-2002). Dessa forma, "[...] a pesquisa fenomenológica, portanto, parte da compreensão de nosso viver não de definições e conceitos -, da compreensão que orienta atenção para aquilo que se vai investigar" (FAZENDA, 2000, p. 63).

Optou-se pela abordagem predominantemente qualitativa, levando em consideração que, nesse tipo de abordagem, interessa apreender as percepções comuns e incomuns presentes na subjetividade das pessoas envolvidas na pesquisa, notadamente na condição de objeto-sujeito (MARQUES et al., 2006). Nesse sentido, pretendeu-se preservar o ambiente natural no qual os sujeitos foram consultados/ ouvidos por ocasião das entrevistas, que, por sua vez, constituíram-se na fonte direta dos dados coletados. A presente pesquisa é fruto/extrato de uma dissertação de mestrado de uma das autoras, a qual foi concluída em abril de 2016 (GONZAGA, 2016).

A investigação foi realizada com vinte professores que atuam no curso de licenciatura em Matemática do Instituto Federal de Educação, Ciência e Tecnologia da Paraíba (IFPB), Campus Cajazeiras. Como instrumentos de coleta dos dados foram utilizados questionários, com o objetivo de fornecer subsídios para a elaboração do perfil desses docentes, e entrevistas semiestruturadas, que, por sua vez, abordavam questões ligadas às concepções de educação, de avaliação da aprendizagem, 
bem como a identificação das práticas e dos instrumentos avaliativos utilizados no contexto analisado.

A pesquisa foi registrada no Comitê de Ética em Pesquisa da Universidade Federal do Ceará, no qual foram observados todos os cuidados éticos necessários para preservação dos participantes. Tendo em vista a preservação da identidade dos participantes da pesquisa, no decorrer da análise, os professores participantes são citados apenas com a inicial "P" (de participante), seguida de uma numeração: $\mathrm{P} 1$, P2, P3, e assim sucessivamente.

As falas dos docentes entrevistados foram analisadas à luz da hermenêutica, a partir da abordagem filosófica de Hans-Georg Gadamer (1997, 1998, 2009). Ao afirmar a necessidade/importância da hermenêutica, Gadamer enfatiza que qualquer situação que envolve a compreensão, necessariamente, envolve também a interpretação. É preciso ir além do que está posto, do que está explícito, na busca da compreensão do sentido, da comunicação.

Muitos aspectos estão envolvidos na atividade hermenêutica, entre eles a função exercida pela linguagem, que expressa a vivência das pessoas. A compreensão é muito específica de cada sujeito. Cada pessoa compreende de uma forma diferente, tendo em vista os fatores ligados às experiências inerentes a cada ser em particular.

Nesse sentido, Gadamer estabelece um comparativo entre o ato de compreender e uma situação de conversa, considerando que o intérprete precisa ouvir o outro que fala e respeitar suas opiniões. O mesmo acontece com a tarefa de compreensão de um texto, em que é preciso deixar o texto falar no horizonte do intérprete. Assim, para Gadamer, o ser que pode ser compreendido é a linguagem, o que se estabelece a partir da fala e da compreensão dessa fala (SCHMIDT, 2012).

Nesse entendimento, as falas foram agrupadas a partir da extração das categorias para análise, seguida da identificação de horizontes comuns presentes nessas falas. Por fim, foi realizado o processo de fusão desses horizontes.

\section{Discussão dos resultados}

Antecedendo as análises relacionadas às concepções de avaliação da aprendizagem, identificadas nas falas dos professores pesquisados, e às práticas que os docentes dizem desenvolver no espaço acadêmico, abriu-se espaço para discorrer sobre a práxis docente no que tange à formação dos licenciandos, a fim de auxiliar a compreensão do ideário, bem como da atuação dos professores no quesito avaliação da aprendizagem no ensino superior, visto que são componentes pedagógicos indissociáveis: formação e avaliação. 


\section{A realização das atividades docentes ligadas à formação de professores de professores no IFPB - Campus Cajazeiras}

Para tratar de aspectos ligados à formação de professores, é importante recorrer à concepção que se tem de cada ação desenvolvida no ambiente escolar e, de modo especial, das atividades inerentes às práticas voltadas para a formação de futuros professores. De acordo com Veiga e D'Ávila, a formação de professores “[...] constitui o ato de formar o docente, educar o futuro profissional para o exercício do magistério. Envolve uma ação a ser desenvolvida com alguém que vai desempenhar a tarefa de educar, de ensinar, de aprender, de pesquisar e de avaliar" (2008, p. 15).

A partir dessa visão, os professores que desenvolvem as atividades docentes ligadas à licenciatura em Matemática foram levados a refletir sobre suas ações no curso, bem como sobre o grau de amplitude ou de complexidade de cada uma delas. Dentre os diversos aspectos abordados, alguns professores apontam como dificuldade a forma como vem sendo conduzido o acesso ao curso de licenciatura. Ao passo que o Exame Nacional do Ensino Médio (Enem) e o Sistema de Seleção Unificada (Sisu) favorecem o aumento das possibilidades de acesso à universidade, ao ensino superior, também provocam uma série de distorções, como ilustram os depoimentos conjuntos citados a seguir:

A gente sente um pouco de dificuldade, porque, devido ao Enem ter várias opções para o aluno escolher o curso, geralmente eles colocam Matemática como sendo a última opção. [...] Mas eu faço um trabalho motivador, mostrando, falando sobre a carreira e aí vem despertar o interesse de alguns desses alunos, e a gente consegue convencer alguns deles a continuar no curso e investir no curso (P4; P11; P13).

Esses professores atribuem o grande índice de evasão do curso à forma como acontece a seleção para ingressá-lo, tendo em vista que uma parcela considerável dos discentes chega ao curso sem ter a devida identificação com a área de Matemática e menos ainda com as atividades ligadas à docência. Dessa maneira, torna-se difícil a prática voltada para a formação, principalmente de cunho pedagógico, uma vez que, "[...] em relação à formação de professores, as instituições ainda [...] deixam muito a desejar, principalmente nas disciplinas mais voltadas para área da educação, pedagógica [...]" (P1; P3; P8). Nessa perspectiva, esses mesmos professores refletem sobre a importância e a complexidade de suas práticas visando à formação do profissional com um melhor e maior nível de qualidade. Por essa razão: 
[...] a gente tenta contribuir da melhor forma possível, porque eu tenho a consciência que minha formação enquanto professor foi muito deficitária. Então, a gente, tendo a oportunidade de trabalhar na formação de professores, tenta melhorar cada vez mais para que sejam futuros professores melhores do que a gente é hoje (P1; P3; P8).

Numa outra perspectiva, essa preocupação com o resultado das ações docentes desenvolvidas na licenciatura vai muito além do que se percebe na sala de aula como resultado imediato em termos de conteúdos específicos. São ações projetadas para o futuro, tendo em vista se tratar de resultados que serão percebidos em médio ou longo prazo, como afirmam os professores no depoimento a seguir:

Porque, a partir do momento que eu tento formar um profissional de boa qualidade, teórico, humano, que tenha senso crítico, eu fico na preocupação. Quando eu aprovo um aluno que, às vezes, você acha que a capacidade de teoria é baixa, aí você fica se perguntando: 'será que mais à frente ele vai conseguir?'. Você se enche de pergunta, é a parte da teoria, a parte didática, a parte prática (P7; P10; P13; P17; P19).

Para esses professores, o que deve ser levado em consideração é o conjunto de habilidades e competências necessárias ao processo de formação e atuação do futuro docente, numa perspectiva mais ampla, que contemple as dimensões técnica, estética, ética e política, que, por seu turno, darão suporte à competência pedagógica como um todo (RIOS, 2010). Nesse processo, o discente, futuro professor, precisa ser enxergado como um ser em sua completude. A formação precisa ser vislumbrada numa visão mais abrangente, mais complexa, como ilustra o depoimento a seguir:

[...] eu procuro desenvolver a minha prática sempre atrelando realmente a essa perspectiva emancipatória que os nossos alunos, futuros professores, precisam enxergar, perceber o futuro aluno dele realmente com um olhar especial. Ele precisa se dedicar não somente à prática, ao ensino de Matemática, ao conteúdo de Matemática [...]. Tento construir neles uma visão humanística do ser (P12; P14; P15).

Mesmo diante das muitas especificidades da profissão e das dificuldades enfrentadas no exercício da docência, uma boa parcela dos professores entrevistados revela o sentimento de realização em se tratando de sua atuação no curso de licenciatura em Matemática: "Eu me sinto realizado, me sinto, vamos dizer, feliz por ser professor de futuros professores, portanto: professor formador" (P2; P6; P9; P18).

Ao passo que os professores se posicionaram em relação a suas práticas individuais, foram motivados também a refletir sobre como essas práticas são pensadas e desenvolvidas no âmbito da instituição, do curso como um todo.

O primeiro aspecto mencionado está voltado para o perfil do egresso que se pretende formar no curso. Nesse sentido, é destacado o papel norteador do projeto político-pedagógico do curso e a vinculação das ações desenvolvidas pelos professores a esse perfil de aluno/professor que se pretende formar, o que acaba direcionan- 
do uma série de ações pedagógicas no sentido de atingir esses objetivos relacionados ao perfil do profissional que se pretende formar. Assim:

A ação dos professores visa tornar aquele perfil do aluno egresso do curso algo verdadeiro, algo compatível com o que consta nos documentos oficiais do curso, como o PPC do curso de licenciatura [...]. Formar professores para atuar nas salas de aula, mais especificamente no nosso estado (P1; P2; P6; P7; P8; P9; P10; P11).

Outros participantes, por sua vez, reconhecem o grande desafio que consiste em formar professores, pensar sob uma nova perspectiva a ação docente numa instituição que, por muito tempo, teve em sua essência, basicamente, a formação técnica. Dessa forma, afirmam ser:

[...] algo novo dentro de uma instituição que guarda historicamente os traços de uma formação estritamente técnica e tecnicista e que, de um certo modo, agora se vê inserida nos seus contextos, no seu meio. A formação de professores, então, é algo novo, que, ao mesmo tempo, é desafiador. [...]. Então, por um lado, ele é complexo, porque ainda traz as amarras do tecnicismo, mas, por outro lado, é desafiador, porque mostra a possibilidade de os institutos terem uma formação mais humanista da própria formação, da própria compreensão do mundo e do trabalho (P16; P18).

Pensando nesses desafios, foram destacados alguns aspectos, os quais, na visão dos professores, podem comprometer ou, de certa forma, dificultar a ação de formação de docentes no cenário pesquisado. A busca pela compreensão dos processos nos quais se desenvolvem a aprendizagem de modo geral, de como esses processos "[...] estão se concretizando. Acho que essa é a questão mais desafiadora do professor" (P12; P16; P18).

Outro ponto mencionado tem relação com a postura do professor em sala de aula, em que, nos últimos anos, observa-se um grande avanço no quantitativo de ofertas de vagas/matrículas, no entanto, nesse sentido, o grande desafio é motivar o educando a permanecer na escola. Esse é um desafio posto à formação do professor, pois, como afirmam os participantes: “[...] nós, como professores, como educadores, precisamos rever nossas posturas, nossos mecanismos para que essa permanência possa acontecer de fato e de direito" (P3; P14).

Relatados todos os aspectos que compõem a formação do professor, a partir de uma visão mais ampla de educação, de sistema educacional, na sequência, foram abordados aspectos relacionados às concepções que esses docentes têm sobre a avaliação da aprendizagem e os fatores que norteiam as práticas voltadas para a realização de tal atividade no âmbito da formação de professores no contexto pesquisado. 


\section{As concepções de avaliação da aprendizagem dos professores do curso de licenciatura em Matemática do IFPB - Campus Cajazeiras}

Para se compreender alguns dos aspectos mencionados pelos professores entrevistados no tocante a suas concepções de avaliação da aprendizagem, foram utilizados fundamentos da hermenêutica, com enfoque em Gadamer. Nesse processo de compreensão, é importante considerar os aspectos da temporalidade e da historicidade, tendo em vista que a identidade docente é constituída de diversos fatores, entre eles, fatores socialmente construídos ou constituídos, com os quais se pode interagir nos momentos de reflexão e busca de definições de determinados conceitos. Dessa forma, é interessante destacar também a compreensão do que venham a ser esses "preconceitos" na abordagem gadameriana, em que a essa expressão é atribuído o significado de concepção prévia, as ideias que se tem acerca de determinados assuntos, a compreensão preliminar construída pelo sujeito a partir das experiências vivenciadas ao longo de sua existência.

Percebe-se que, para muitos dos docentes entrevistados, a avaliação ainda está muito ligada à aplicação de testes, como se percebe neste relato: "Avaliar é testar se o aluno de fato está absorvendo aquele conhecimento" (P1; P2, grifo nosso).

A avaliação da aprendizagem, pensada nessa perspectiva, encaixa-se no período denominado por Thereza Penna Firme (1994) como primeira geração da avaliação. Nessa perspectiva, de acordo com a autora, os estudiosos e usuários da avaliação tinham como preocupação central a "[...] elaboração de instrumentos ou testes para verificação do rendimento escolar [...], testes e exames eram indispensáveis na classificação de alunos para se determinar seu progresso" (1994, p. 108).

Ainda há, por parte de alguns professores, um forte direcionamento às práticas mais tradicionais em se tratando de avaliação da aprendizagem, nas quais se valoriza fortemente a utilização de provas como instrumentos de avaliação. "Nós temos basicamente uma avaliação em que a gente trabalha a prova, aquela prova bem tradicional mesmo, e na Matemática a gente não foge muito disso. Tenta medir a capacidade de assimilação do aluno baseado em prova" (P4; P5; P7; P8; P13). Na visão desses profissionais, a prova ainda é vista como única possibilidade de avaliação, atribuindo-lhe a função exclusiva de instrumento de verificação da aprendizagem do estudante.

De outro modo, há docentes que mencionam a avaliação como uma prática que deve ir além da simples aplicação de testes ou atribuição de notas. Nesse caso, a avaliação é pensada ou desenvolvida de maneira contínua, contemplando aspectos que vão muito além de uma nota, de uma prova escrita, como se pode observar nos relatos a seguir: 
A avaliação, para mim, não é só a questão de analisar uma nota ou uma prova, não. [...] Eu acho que ela tem que ser de maneira continuada, de maneira qualitativa e quantitativa [...], analisar todos os aspectos em relação ao aluno, à questão dele, da participação, da presença, de como ele lida na questão da resolução de exercícios, não só a prova em si; a avaliação tem que ser um conjunto de tudo, de todos os aspectos durante aquele ambiente, aquele momento da sala de aula (P3; P6; P9; P16).

Nesse contexto, é importante enfatizar que a avaliação assume funções diferenciadas, sendo mediada pela concepção que norteia cada prática. O próprio instrumento "prova" assume funções diferenciadas diante das concepções pelas quais tal instrumento é concebido.

$\mathrm{Na}$ ação de avaliar a aprendizagem do aluno em sala de aula, é imprescindível que o professor também se perceba como sujeito envolvido no processo de avaliação, passando a considerar que os resultados podem ocorrer em decorrência de suas práticas, das metodologias adotadas em sala de aula. Nesse sentido, alguns docentes apresentam uma reflexão interessante sobre suas práticas, destacando o nível de complexidade presente no ato de avaliar:

Avaliar é algo muito complexo, muito subjetivo e nada quantitativo, como muita gente pensa. Então, avaliar é tentar enxergar no outro, no seu aluno, também o que você tentou ensinar para ele. Então é um feedback daquilo que você passou para ele, sempre é necessário você ter uma visão não somente quantitativa daquele conteúdo, daquele assunto, mas estar atrelando os feedbacks para que você possa fazer uma avaliação global (P13; P14; P18).

Outro aspecto interessante é a valorização dos feedbacks. No processo de interação entre docentes e discentes, são várias as oportunidades de o professor se enxergar a partir de sua ação. Isso acontece com base nos retornos dados pelos estudantes em decorrência das práticas desenvolvidas em sala de aula. A ação reflexiva do docente faz toda a diferença na forma de encarar o processo educativo. Com a avaliação da aprendizagem não é diferente, o professor precisa se ver dentro do processo e, diante de determinadas situações, rever suas práticas, tendo em vista os objetivos traçados para o público com o qual trabalha e os resultados obtidos a partir de cada ação.

Ao se pensar a avaliação a partir dessa perspectiva, identificam-se outros aspectos inerentes à ação docente que fazem a diferença de acordo com a concepção adotada por cada profissional. O planejamento, os princípios e as funções da avaliação são direcionados para um olhar mais positivo da ação avaliativa. Dessa forma, destacam-se os seguintes relatos: 
[...] avaliação é um instrumento que o professor tem para ver se efetivamente o planejamento dele, os objetivos que ele traçou para aquele semestre, bimestre, para aquela disciplina, enfim, estão sendo concretizados. Então, o professor avalia para fazer um diagnóstico, para saber se realmente a atuação dele está dando certo, está funcionando. Se estiver funcionando, ótimo, ele vê que está no caminho certo, vê se ele pode prosseguir. Caso o professor perceba que os alunos não se saíram bem na avaliação, então é necessário que ele pare, repense e veja onde é que está o erro (P7; P8; P11; P12; P15; P17).

Mesmo havendo ainda um direcionamento das práticas dos professores para a utilização de provas, para a valorização de notas em detrimento de outras práticas, percebem-se também práticas permeadas pela intenção de se realizar a avaliação numa perspectiva diferenciada. Com base nas concepções de avaliação da aprendizagem mencionadas pelos professores, foi destacada também a forma como eles se veem nesse processo, a partir das práticas desenvolvidas em sala de aula, numa relação direta entre teoria e prática.

\section{As práticas de avaliação da aprendizagem no curso de licenciatura em Matemática do IFPB - Campus Cajazeiras}

Com a intenção de trazer à tona fatores inerentes às práticas dos professores, enfatizando a maneira como eles se veem em sala de aula e a reflexão estabelecida a partir dos questionamentos voltados para essas práticas, abordaram-se aspectos constitutivos das práticas voltadas para a avaliação da aprendizagem, destacando a maneira como cada um se enxerga dentro desse processo. Um dos primeiros fatores evidenciados está voltado para o aspecto da reprodução. Apesar de muitos professores destacarem sua preocupação em adotar práticas diferenciadas em se tratando de avaliação, há alguns indícios de contradição quando eles descrevem suas práticas.

[...] a teoria, para os meus alunos, eu repasso isso em forma de teoria para eles [...], para mostrar uma formação solidificada, e aí, quando eles vão reproduzir isso em termos de casos particulares, que são os exercícios práticos que vão mostrar o funcionamento daquele determinado resultado, eu espero que eles consigam reproduzir, seja numa avaliação sem consulta e individual, onde eles vão tentar usar da memória e do que aprenderam [...] (P1; P2; P13; P17).

No relato supracitado, percebe-se, além do aspecto voltado para a reprodução, a técnica de repetição. É descrito um processo que, aparentemente, considera a memorização, a repetição de exercícios, a fim de reproduzir exemplos, na busca de resultados preestabelecidos. A seguir, destacam-se alguns exemplos: 
[...] eu tento incitar com questões mais elaboradas nos trabalhos deles, dar uma resposta num determinado passo que eu estou pedindo para eles seguirem, com isso eu espero, naquela situação bem localizada, bem especificada, mas que atende ao conteúdo como um todo, em termos de qualidade de conhecimento, que eles venham, individualmente ou isoladamente, pedir a minha contrapartida, em termos de compreensão [...]. No caso da Matemática, resolução de exercícios faz o aluno querer investigar mais, [...] com que o aluno tenha mais interesse, até mesmo na questão de ele ter vontade de aprender (P1; P3; P8).

As práticas parecem múltiplas e até divergentes em alguns momentos, o que pode ser ilustrado ou evidenciado pelas falas dos participantes. Apesar de alguns professores destacarem a utilização de exercícios na busca de uma efetividade no processo de apreensão de conhecimentos por parte dos alunos, outros já visualizam a sua atuação numa perspectiva mais crítica, partindo dos olhares dos discentes sobre essas práticas, enfim, compreendendo que há um grau de amplitude maior a partir do que se desenvolve em sala de aula em termos de conteúdos.

Então, você pode avaliar um aluno até mesmo a partir de seu comportamento de questionar, de participar, de interagir na aula. [...]. Então, se eu aplico uma avaliação só escrita, aquele aluno que tem um potencial na oratória vai deixar a desejar; não que ele não saiba, não que ele não tenha assimilado, porque a sua limitação individual particular não nos permite avaliar o seu potencial numa prova escrita. Então, eu acredito que avaliar vai além de aplicar uma prova (P10; P12; P15; P16; P17).

Nesse sentido, o ato de avaliar se estende a muitas outras práticas, que vão além da simples aplicação de uma prova ou até mesmo da utilização de exercícios de fixação de conteúdos. Ao passo que o educando interage com conteúdos nos quais ele consegue visualizar uma aplicabilidade, mais facilmente ele encontra sentido no que está estudando, visualiza possibilidades de utilização em suas práticas e vivências cotidianas, assim, as aulas e as atividades ganham novos significados. Além disso, é importante considerar também o conhecimento que os discentes trazem consigo nesse processo de construção e reelaboração de conceitos, sobre os quais o professor deve atuar pedagogicamente:

Justamente procurando identificar no aluno todo esse conhecimento prévio que ele traz e a atuação dele na participação em sala de aula, fazendo aquele processo de, no momento da avaliação, ter a noção do que aconteceu antes, do que está acontecendo durante a avaliação e, numa perspectiva futura, do que pode acontecer após a avaliação (P6; P9; P10; P11).

Por último, mas não menos importante, destacou-se também a prática da autoavaliação como instrumento indispensável para uma prática reflexiva do professor, de modo especial a avaliação da aprendizagem: "Eu faço a minha autoavaliação do que passo. Segundo: peço que eles façam uma autoavaliação do que eles assimilaram. A partir daí é que eu faço uma avaliação de conteúdo" (P14; P18). Essa ação de reflexão vai muito além, ela motiva o exercício da prá- 
xis, ou seja, a ação docente refletida. E, nessa ação refletida, é preciso levar em consideração os sinais emitidos pelos alunos como sujeitos ativos de um processo, sinais esses que darão suporte para ações futuras em sala de aula.

Ao abordar questões voltadas para os instrumentos de avaliação empregados pelos docentes entrevistados, percebe-se claramente que os professores, sobremaneira os das disciplinas do núcleo específico do curso, recorrem à utilização de provas com maior intensidade, embora, em determinadas situações, percebam a necessidade de utilizar também outros recursos, como se observa no excerto a seguir:

A gente ainda é muito apegado à avaliação tradicional, à prova de fato, que é uma coisa que já vem há muito tempo. Mas a gente tenta outros meios, como seminários, grupos de estudos; hoje também está muito em evidência a questão das multimídias que a gente tenta trazer para a sala de aula também para que possa agregar algo mais, mas assim, na grande maioria, a gente ainda é tradicionalista, que é aquela prova escrita, que, no final, tem que atribuir uma nota $[. .$.$] (P2; P5; P7; P11; P13; P19).$

Por meio desse depoimento, intui-se que, para alguns desses profissionais, apesar da busca e do reconhecimento da necessidade de se inovar no que concerne a práticas avaliativas, ainda é muito forte a herança da Pedagogia tradicional. Os professores atribuem às disciplinas e aos conteúdos trabalhados a inviabilidade de utilizarem métodos ou estratégias mais voltados para uma prática diversificada pertinente à avaliação da aprendizagem.

Todavia, alguns docentes, ao falarem sobre suas práticas, fazem referência a uma prática de avaliação contínua, que considera todas as fases do processo de ensino-aprendizagem, que visa detectar as dificuldades para, a partir disso, adotar meios de superá-las, como é mencionado no relato que se segue:

Meu processo de ensino-aprendizagem é avaliado justamente em cima da avaliação contínua. Eu procuro sempre avaliar de forma contínua, vendo o desempenho dos alunos, vendo onde é que estão os pontos fracos, tentando ajudá-los para que eles consigam superar aqueles pontos fracos e daí chegar ao meu objetivo, que é passar conhecimentos para eles, e ao objetivo deles, que é adquirir (P9; P12).

Tais depoimentos conduzem a uma compreensão de que a avaliação ou o ato de avaliar a aprendizagem como um todo exige uma tomada de consciência que vai além da ação isolada do professor no momento de avaliar. Tal ação envolve fatores que são percebidos nas diversas nuances da prática docente, desde a concepção do professor ou da escola como um todo sobre o que é avaliar até o desenvolvimento da ação propriamente dita. 


\section{Considerações finais}

A avaliação educacional, de modo geral, ainda é associada a muitos entraves na prática pedagógica como um todo. Em se tratando de avaliar a aprendizagem, essas dificuldades se intensificam, tendo em vista os diversos aspectos em jogo nessa prática tão complexa. Os sujeitos envolvidos nesses contextos trazem consigo muitas especificidades, que, por sua vez, tornam o processo ainda mais delicado.

Ao se permitir a reflexão sobre os diversos aspectos que norteiam as concepções de avaliação da aprendizagem e, consequentemente, das diversas instâncias consideradas na ação de avaliar, foi possível compreender que toda a ação pedagógica é norteada pela maneira como se pensa tal ação no processo educativo como um todo. Não há como se analisar determinado aspecto da ação pedagógica ou da ação docente se não se considera o contexto no qual tal ação é desenvolvida.

A partir das análises voltadas especificamente para as práticas de avaliação da aprendizagem empreendidas pelos professores participantes da pesquisa, observou-se que ainda há uma herança forte no que diz respeito à prática dos exames. Na atuação desses profissionais, evidenciou-se o uso frequente da prova como instrumento de avaliação, apesar de perceberem e afirmarem as necessidades da ampliação das possibilidades dessa utilização e da adoção de outros instrumentos avaliativos. Algumas possibilidades citadas foram seminários, debates e trabalhos em grupos, contudo, em determinadas situações, ou em relação a determinadas disciplinas, ainda parece distante a possibilidade de abrir mão do emprego exclusivo do instrumento prova como prática avaliativa, tendo em vista a dificuldade de se mobilizar os conteúdos sob outras formas de abordagem, diferentes do modelo pedagógico tradicional.

Num processo de avaliação, todos os envolvidos precisam ter voz ativa. Sendo assim, deve-se considerar que todos os sujeitos têm suas inquietações, seus olhares diferenciados acerca de um mesmo fenômeno, por ocuparem posições diferenciadas. Nessa perspectiva, é importante que os alunos, professores em formação, tenham esse espaço de diálogo garantido.

A investigação não se dá por acabada, tendo em vista que o próprio contexto e as relações existentes nele se transformam a cada dia. As exigências educacionais se constituem e se reconstituem numa velocidade que o próprio sistema educacional tem dificuldade de acompanhar. Assim também acontece com as práticas que são pensadas e implementadas no ambiente escolar, haja vista que os sujeitos envolvidos na ação didática também se encontram em constantes modificações. 


\section{Referências}

ANDRIOLA, W. B. Avaliação do aprendizado docente: estudo com professores de escolas públicas. Educar em Revista, Curitiba, n. 46, p. 141-158, 2012.

BIESTA, G. Boa educação na era da mensuração. Cadernos de Pesquisa, São Paulo, v. 42, n. 147, p. $808-825,2012$.

ESTEBAN, M. T. A dimensão reflexiva da avaliação. TVE Brasil. Salto para o Futuro, fev. 2004. (Entrevista). Disponível em: <www.tvebrasil.com.br/salto/entrevista/maria_teresa_esteban\%20. htm>. Acesso em: 25 mar. 2016.

. (Org.). Escola, currículo e avaliação. 3. ed. São Paulo: Cortez, 2008.

FAZENDA, I. (Org.). Metodologia da pesquisa educacional. 6. ed. São Paulo: Cortez, 2000.

FIRME, T. P. Avaliação: tendências e tendenciosidades. Ensaio: Avaliação de Políticas Públicas Educacionais, Rio de Janeiro, v. 1, n. 2, p. 5-12, 1994.

GADAMER, H.-G. O problema da consciência histórica. Rio de Janeiro: FGV, 1998.

Verdade e método. Petrópolis: Vozes, 1997.

. Verdade e método. Petrópolis: Vozes, 2009.

GATTI, B. A. Professor e a avaliação em sala de aula. Estudos em Avaliação Educacional, São Paulo, n. 27, p. 97-114, 2003.

GONZAGA, A. E. de S. Das concepções às práticas de avaliação: um estudo sobre as práticas avaliativas no curso de licenciatura em Matemática do Instituto Federal de Educação, Ciência e Tecnologia da Paraíba - Cajazeiras. 2016. 121 f. Dissertação (Mestrado) - UFC, Fortaleza, 2016.

HOFFMANN, J. O jogo do contrário em avaliação. Porto Alegre: Mediação, 2005.

LIBÂNEO, J. C. Didática. São Paulo: Cortez, 1994.

MARQUES, H. R. et al. Metodologia da pesquisa e do trabalho científico. Campo Grande: UCDB, 2006.

MORETTO, V. P. Planejamento: planejando a educação para o desenvolvimento de competências. 5. ed. Petrópolis: Vozes, 2010.

NÓVOA, A. Os professores na virada do milênio: do excesso dos discursos à pobreza das práticas. Educação e Pesquisa, São Paulo, v. 25, n. 1, p. 11-20, 1999.

PERRENOUD, P. Avaliação: da excelência é regulação das aprendizagens. Porto Alegre: Artmed, 1999.

POLIDORI, M. M.; MARINHO-ARAÚJO, C.; BARREYRO, G. B. Sinaes: perspectivas e desafios na avaliação da educação superior brasileira. Ensaio: Avaliação e Políticas Públicas em Educação, Rio de Janeiro, v. 14, n. 53, p. 425-436, out./dez. 2006.

RIOS, T. A. Compreender e ensinar: por uma docência da melhor qualidade. 8. ed. São Paulo: Cortez, 2010. 
SAVIANI, D. Pedagogia histórico-crítica: primeiras aproximações. 11. ed. Campinas: Autores Associados, 2011.

SCHMIDT, L. K. Hermenêutica. Petrópolis: Vozes, 2012.

SILVA, J. F. da. Avaliação do ensino e da aprendizagem numa perspectiva formativo-reguladora. In: SILVA, J. F. da. et al. (Org.). Práticas avaliativas e aprendizagens significativas: em diferentes áreas do currículo. 10 ed. Porto Alegre: Mediação, 2013. p. 9-22.

Avaliação educacional: fundamentos teóricos e relação com a política educacional. In: SEMINÁRIO REGIONAL DE POLÍTICA E ADMINISTRAÇÃO DA EDUCAÇÃO DO NORDESTE, 7, 2012, Recife. Cadernos Anpae. Recife: UFPE, 2012. p. 1-12.

VEIGA, I. P. A.; D’ÁVILA, C. M. (Org.). Profissão docente: novos sentidos, novas perspectivas. Campinas: Papirus, 2008.

VIANNA, H. M. Avaliação educacional: teoria, planejamento, modelos. São Paulo: Ibrasa, 2000.

VILLAS BOAS, B. M. Portfólio, avaliação e trabalho pedagógico. Campinas: Papirus, 2004. 